\title{
Hydrogenation of Phenol with Different Catalysts in Supercritical Alcohol
}

\author{
Zhaoni Kong, Jianping Zhang* \\ Faculty of Civil Engineering, Kunming University of \\ Science and Technology, Kunming, China \\ e-mail: 237071828@qq.com
}

\author{
Qingqing Guan, Junjie Gu \\ Faculty of Environmental Science and Engineering \\ Kunming University of Science and Technology \\ Kunming, China
}

\begin{abstract}
Pd/C, $\mathrm{Ni} / \mathrm{SiO}_{2}-\mathrm{Al}_{2} \mathrm{O}_{3}$ and $\mathrm{Ru} / \mathrm{C}$ were used for hydrogenation of phenol in supercritical alcohol system. The results indicate that $\mathrm{Pd} / \mathrm{C}$ is an efficient catalyst for hydrogenation of phenol in supercritical alcohol system, over $80 \%$ phenol was removed at initial $40 \mathrm{~min}$ and cyclohexane, cyclohexanol and cyclohexanone are main products. Since products such as 2 - ethyl phenol, 4 - ethyl phenol, 2-methyl -5isopropyl phenol and 1-methoxy-4-isopropyl benzene are produced with $\mathrm{Ni} / \mathrm{SiO}_{2}-\mathrm{Al}_{2} \mathrm{O}_{3}$ and 2 - ethyl phenol and dibutyl phthalate are found with $\mathrm{Ru} / \mathrm{C}, \mathrm{Ni} / \mathrm{SiO}_{2}-\mathrm{Al}_{2} \mathrm{O}_{3}$ and $\mathrm{Ru} / \mathrm{C}$ are not effective catalysts for hydrogenation reaction in supercritical alcohol system. Those two catalysts increases the ethylation reaction dramatically, rather than hydrogenation reaction.
\end{abstract}

Keywords-Phenol; Hydrogenation; Supercritical alcohol.

\section{INTRODUCTION}

With the impact of fossil fuels on the environment, there is an increasing interest on quest for suitable, environmentally friendly alternatives for fuels. Biomass fuels are considered as one option. But the quality of biofuel from liquefaction process is low, containing aromatic compounds and high oxygen content. Hydrogenation is the way to convert aromatic compounds to fuels such as hydrocarbon, alcohol, ketone and to remove oxygen totally or partly under $\mathrm{H}_{2}$ pressure, which is a proven method for upgrading biofuel to the required quality [1].

Hydrogenation of biofuel usually is carried out in medium such as dichloromethane, hexane [2]. A supercritical fluid is substance at a temperature and pressure above its critical point, it can effuse through solids like a gas, and dissolve materials like a liquid. Comparing with supercritical water at temperatures and pressures that $\mathrm{Tc}=$ $374{ }^{\circ} \mathrm{C}, \mathrm{Pc}=22.1 \mathrm{MPa}$, the critical point of alcohol is $\mathrm{Tc}=$ $241^{\circ} \mathrm{C}, \mathrm{Pc}=6.14 \mathrm{MPa}$ [3]. Thus, it is more potential to use supercritical alcohol as a green medium for chemical reactions.

Phenol is a typical aromatic pollutant. A recent study indicated that phenols were the major byproduct of noncatalytic gasification and liquefaction, accounting for 7-20 $\mathrm{wt} \%$ of biomass tar [4] and over $25 \mathrm{wt} \%$ of coal tar [5]. Studies about hydrogenation of phenol provide a better understanding of tar conversion and biofuel update. A detailed study of hydrogenation of phenol is thus important for the sake of environmental and energy-conversion concerns.

In this work, the catalytic hydrogenation of phenol in supercritical alcohol with $\mathrm{Ru}, \mathrm{Ni}$ and $\mathrm{Pd}$ was investigated.
The work tried to give better insights into the hydrogenation of phenol in supercritical alcohol system.

\section{MATERIALS AND METHODS}

\section{A. Materials}

There noble metal catalysts supported on carbon $(\mathrm{Ru} / \mathrm{C}$ and $\mathrm{Pd} / \mathrm{C}$ ) and one typical transition metal catalyst supported on silica-alumina $\left(\mathrm{Ni} / \mathrm{Al}_{2} \mathrm{O}_{3}-\mathrm{SiO}_{2}\right)$ were purchased from Sigma-Aldrich. The noble metal catalysts contain $5 \mathrm{wt} \% \mathrm{Ru}$, $\mathrm{Pt}$ and $\mathrm{Pd}$ respectively and the transition metal catalyst has $65 \mathrm{wt} \% \mathrm{Ni}$, Some details of which can be found in our previous works [6].

Phenol and chemicals were also purchased from SigmaAldrich.

\section{B. Hydrogenation of phenol}

In a typical experiment, $0.0196 \mathrm{~g}$ phenol and $0.0098 \mathrm{~g}$ catalyst such as $\mathrm{Ru} / \mathrm{C}, \mathrm{Pd} / \mathrm{C}$ and $\mathrm{Ni} / \mathrm{Al}_{2} \mathrm{O}_{3}-\mathrm{SiO}_{2}(50 \mathrm{wt} \%$ ), was loaded into a reactant together with $391 \mu \mathrm{L}$ fresh alcohol. After repeatedly charging and venting with hydrogen, the reactant was filled to $3 \mathrm{MPa}$ with hydrogen.

A Techne fluidized sand bath (model SBL-2) with a Techne TC-8D temperature controller kept the reactant at the desired temperatures. After a certain time of heating, the reactant was removed and cooled down to room temperature by a fan.

The process and equipment used were depicted in detail in our previous works [7].

\section{Sample analysis}

The gaseous products were analyzed by an Agilent Technologies model 7820A gas chromatograph (GC) with a thermal conductivity detector (GC-TCD) using a $15 \mathrm{ft} \times 1 / 8$ in. i.d. stainless steel column, packed with $60 \times 80$ mesh Carboxen 1000 (Supelco). Argon served as the carrier gas.

After analyzing the gas fraction, the reactants were opened to recover the liquid and solid fractions. $10 \mathrm{~mL}$ of dichloromethane was added and removed to the reactant three times, before the solid products were collected and filtered. The solid fraction was recovered to test the life of the catalyst. The liquid fraction was analyzed by a GC-MS (PE SQ 8T-680) equipped with Elite-5MS capillary column or DB-5 capillary column and qualified by an Agilent Technologies model 7820A gas chromatograph with a flame ionization detector (GC-FID) using a $30 \mathrm{~m} \times 0.320 \mathrm{~mm}$ stainless steel column. 


\section{RESUlts AND DiscusSION}

\section{A. The effect of $P d / C$}

The effect of $\mathrm{Pd} / \mathrm{C}$ on hydrogenation process was investigated firstly. The results from experiments of hydrogenation of phenol in supercritical alcohol were conducted at 300,350 and $400{ }^{\circ} \mathrm{C}$, with $0.5(\mathrm{~g} / \mathrm{g})$ catalyst loading. As shown in Figure 1, the results show that the hydrogenation efficiencies at base case can reach almost $100 \%$ after 120 min re-actions. The phenol was converted rapidly, even at lower temperature $300{ }^{\circ} \mathrm{C}$, over $80 \%$ phenol was removed at initial $40 \mathrm{~min}$. Comparing with non-catalytic process that phenol was hardly converted at similar conditions, the results indicate that $\mathrm{Pd} / \mathrm{C}$ is an efficient catalyst for hydrogenation of phenol in supercritical alcohol system.

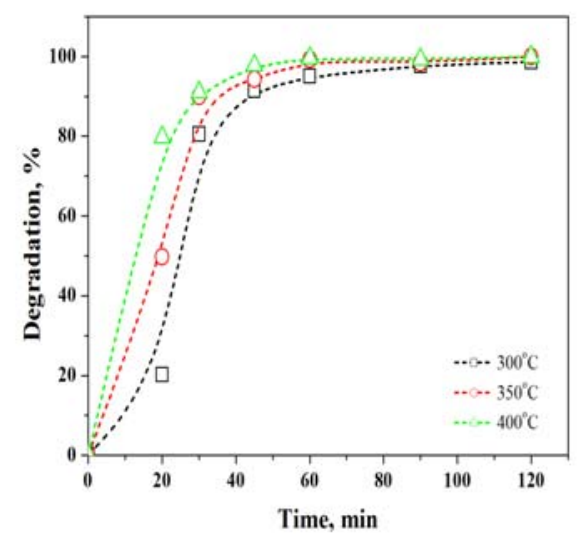

Figure 1. Hydrogenation degradation of phenol in supercritical ethanol by $\mathrm{Pd} / \mathrm{C}$ catalyst.

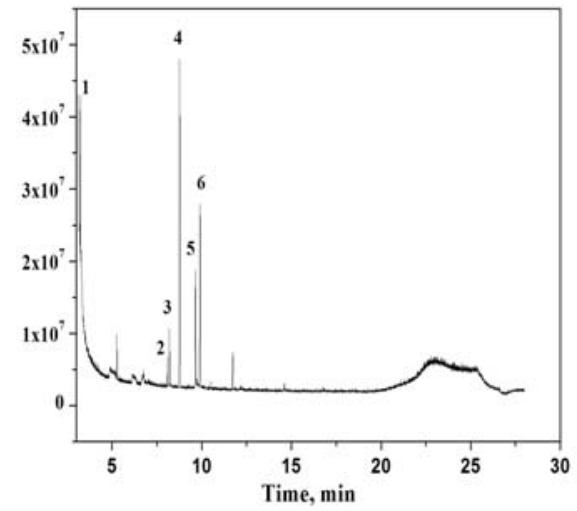

Figure 2. The total ion chromatogram of the liquid products of hydrogenation of phenol in supercritical ethanol catalyzed by $\mathrm{Pd} / \mathrm{C}$ catalyst.
The chromatogram of hydrogenation products of phenol at $350 \mathrm{oC}$ and $45 \mathrm{~min}$ is also shown in Fig. 2. The main types of the products change slightly with time and temperature. The results of the products of hydrogenation of phenol are also shown in table 1 . The results indicate that besides cyclohexane, cyclohexanol and cyclohexanone, Ethoxy cyclohexane and ethoxybenzene are also found.

Cyclohexane, cyclohexanol and cyclohexanone are produced by the reaction of phenol with hydrogen, meanwhile Ethoxy cyclohexane and ethoxybenzene might be from the reaction of by-products of hydrogenation with alcohol.

TABLE I. THE GC-MS (ELITE-5MS) RESULTS OF THE LIQ-UID PRODUCTS OF HYDROGENATION OF PHENOL IN SUPER-CRITICAL ETHANOL CATALYZED BY PD/C CATALYST.

\begin{tabular}{lll}
\hline Peaks & Time/min & Substance \\
\hline 1 & 3.22 & cyclohexane \\
2 & 8.09 & cyclohexanol \\
3 & 8.19 & cyclohexanone \\
4 & 8.76 & ethoxy cyclohexane \\
5 & 9.64 & phenol \\
6 & 9.90 & ethoxybenzene \\
\hline
\end{tabular}

Thus, $\mathrm{Pd} / \mathrm{C}$ is an effective catalyst for hydrogenation in supercritical alcohol system, a rapid hydrogenation reactions can be achieved by using $\mathrm{Pd} / \mathrm{C}$. But it also should be noted that some byproducts such as ethoxy cyclohexane and ethoxybenzene are found, which are mainly from the ethylation reaction. The supercritical alcohol can serve as efficient medium for hydrogenation by $\mathrm{Pd} / \mathrm{C}$ catalysts, but some undesired by-products are also found since alcohol can also serve as reactant during the hydrogenation process.

\section{B. The effect of $\mathrm{Ru} / \mathrm{C}$ and $\mathrm{Ni} / \mathrm{Al}_{2} \mathrm{O}_{3}-\mathrm{SiO}_{2}$}

In this section, the effect of $\mathrm{Ru} / \mathrm{C}$ and $\mathrm{Ni} / \mathrm{Al}_{2} \mathrm{O}_{3}-\mathrm{SiO}_{2}$ on hydrogenation process was also investigated. At $350{ }^{\circ} \mathrm{C}$ and $60 \mathrm{~min}$, over $80 \%$ phenol was converted by those two catalysts.

TABLE II. THE GC-MS (DB-5) ANALYSIS RESULTS OF THE LIQUID PRODUCT OF HYDROTREATMENT OF PHENOL IN SUPERCRITICAL ETHANOL CATALYZED BY NI/SIO$-\mathrm{AL}_{2} \mathrm{O}_{3}$

\begin{tabular}{lll}
\hline Peaks & Time/min & Substance \\
\hline 1 & 5.32 & phenol \\
2 & 6.23 & 2-ethyl phenol \\
3 & 6.36 & 4-ethyl phenol \\
4 & 6.79 & 2-methyl-5-isopropyl phenol \\
5 & 6.99 & 1-methoxy-4-isopropyl benzene \\
\hline
\end{tabular}

TABLE III. THE GC-MS (DB-5) ANALYSIS RESULTS OF THE LIQUID PRODUCT OF HYDROTREATMENT OF PHENOL IN SUPERCRITICAL ETHANOL CATALYZED BY RU/C CATALYST

\begin{tabular}{lll}
\hline Peaks & Time/min & Substance \\
\hline 1 & 5.32 & phenol \\
2 & 6.23 & 2-ethyl phenol \\
3 & 9.11 & dibutyl phthalate \\
\hline
\end{tabular}

But it should be noted that the hydrogenation products by using those two catalysts are undesired products. Using 
$\mathrm{Ni} / \mathrm{SiO}_{2}-\mathrm{Al}_{2} \mathrm{O}_{3}$, by-products such as 2 - ethyl phenol, 4 ethyl phenol, 2-methyl -5-isopropyl phenol and 1-methoxy4-isopropyl benzene are produced. The results indicate that $\mathrm{Ni} / \mathrm{SiO}_{2}-\mathrm{Al}_{2} \mathrm{O}_{3}$ increases the ethylation reaction dramatically, rather than hydrogenation reaction. Thus, $\mathrm{Ni} / \mathrm{SiO}_{2}-\mathrm{Al}_{2} \mathrm{O}_{3}$ can't achieve hydrogenation of phenol in supercritical alcohol system due to alcohol serves as reactant for ethylation.

Similar results are found by using $\mathrm{Ru} / \mathrm{C}$. 2 - ethyl phenol and dibutyl phthalate are found as main products during this process, which are also by-products from the ethylation reaction. Since those products are undesired products and can't serve as high quality fuels, both $\mathrm{Ni} / \mathrm{SiO}_{2}-\mathrm{Al}_{2} \mathrm{O}_{3}$ and $\mathrm{Ru} / \mathrm{C}$ are not effective catalysts for hydrogenation reaction in supercritical alcohol system.

\section{CONCLUSIONS}

Hydrogenation of phenol in supercritical alcohol system with $\mathrm{Pd} / \mathrm{C}, \mathrm{Ni} / \mathrm{SiO}_{2}-\mathrm{Al}_{2} \mathrm{O}_{3}$ and $\mathrm{Ru} / \mathrm{C}$ was investigated. The results indicate that $\mathrm{Pd} / \mathrm{C}$ is an efficient catalyst for hydrogenation of phenol in supercritical alcohol system, the hydrogenation efficiencies can reach almost $100 \%$ after 120 min reactions and cyclohexane, cyclohexanol and cyclohexanone are main products. But $\mathrm{Ni} / \mathrm{SiO}_{2}-\mathrm{Al}_{2} \mathrm{O}_{3}$ and $\mathrm{Ru} / \mathrm{C}$ are not effective catalysts for hydrogenation reaction in supercritical alcohol system, since those two catalysts increases the ethylation reaction dramatically, rather than hydrogenation reaction.

\section{ACKNOWLEDGEMENT}

This work is supported by National Natural Science Foundation of China (21307049) and High Technology
Talent Introduction Project of Yunnan in China (2010CI110), Science and Technology Major Pro-ject of Yunnan Province (2012ZB002). Foundation from Yunnan Natural Science Founda-tion (2013FZ032) and Kunming University (14118583) are also appreciated.

\section{REFERENCES}

[1] Y. Wang, J. Yao, H. Li, D. Su, M. Antonietti, "Highly selective hydrogenation of phenol and derivatives over a $\mathrm{Pd} @$ carbon nitride catalyst in aqueous media," J. Am. Chem. Soc., vol. 133, 2011, pp. 2362-2365, doi: 10.1021/ ja109856y.

[2] C. Xue, X. Zhao, C. Liu, L. Chen, F. Bai, "Prospective and development of butanol as an advanced biofuel," Biotechnology Advances, vol. 31(8), 2013, pp. 1575-1584, doi:10.1016/j.biotechadv.2013.08.004.

[3] C.E. Schwarz, A.J. Villiers, C.B. McClune, G.J.K. Bonthuys, A.J. Burger, J.H. Knoetze, "High pressure phase equilibrium measurements of long chain alcohols in supercritical ethane," The Journal of Supercritical Fluids, vol. 55(2), 2010, pp. 554-565, doi:10.1016/ j.supflu.2010.09.004.

[4] Y.F. Shen, K. Yoshikawa, "Recent progresses in catalytic tar elimination during biomass gasification or pyrolysis-A review," Renewable and Sustainable Energy Reviews, vol. 21, 2013, pp. 371392, doi: 10.1016/ j.rser.2012.12.062.

[5] W. Tang, M. Fang, H. Wang, P. Yu, Q.Wang, Z. Luo, "Mild hydrotreatment of low temperature coal tar distillate: Product composition," Chemical Engineering Journal, vol. 236, 2014, pp. 529-537, doi: 10.1016/ j.cej.2013.09.038.

[6] Q. Guan, T. Mao, Q. Zhang, R. Miao, P. Ning, J. Gu, S. Tian, Q. Chen, $\mathrm{X}$. Chai, "Catalytic gasification of lignin with $\mathrm{Ni} / \mathrm{Al}_{2} \mathrm{O}_{3}-\mathrm{SiO}_{2}$ in sub/supercriticalwater," J. of Supercritical Fluids, vol. 95, 2014, pp. 413-421, doi:10.1016/ j.supflu.2014.10.015.

[7] Q. Guan, P.E. Savage, C. Wei, "Gasification of alga Nannochloropsis sp. in supercritical water," The Journal of Supercritical Fluids, vol. 61, 2012, pp. 139-145, doi: 10.1016/ j.supflu.2011.09.007. 